\title{
Long non-coding RNA NEAT1 promotes ovarian cancer cell invasion and migration by interacting with miR-1321 and regulating tight junction protein 3 expression
}

\author{
MIN LUO ${ }^{1-3}$, LEI ZHANG $^{4}$, HONGYING YANG $^{4}$, KAILI LUO $^{2}$ and CHEN QING ${ }^{2}$ \\ ${ }^{1}$ School of Medicine, Yunnan University, Kunming, Yunnan 650091; ${ }^{2}$ School of Pharmaceutical Sciences and \\ Yunnan Key Laboratory of Pharmacology for Natural Products, Kunming Medical University; \\ ${ }^{3}$ Yunnan Key Laboratory of Quality Standards for Traditional Chinese Medicine and National Medicine, \\ Yunnan University of Chinese Medicine, Kunming, Yunnan 650500; ${ }^{4}$ Department of Gynecology, Yunnan Tumor Hospital \& \\ The Third Affiliated Hospital of Kunming Medical University, Kunming, Yunnan 650118, P.R. China
}

Received March 1, 2020; Accepted June 17, 2020

DOI: $10.3892 / \mathrm{mmr} .2020 .11428$

\begin{abstract}
Previous studies have reported that long non-coding RNAs (lncRNAs) have a significant role in the metastasis of tumors, including ovarian cancer (OC). The aim of the present study was to demonstrate the function and working mechanism of lncRNA nuclear enriched abundant transcript 1 (NEAT1) in OC. The expressions of NEAT1 in OC were measured by reverse transcription-quantitativePCR (RT-qPCR). The effects of NEAT1 on cell proliferation, invasion, migration and epithelial-mesenchymal transition (EMT) were detected by Cell Counting Kit-8, transwell and wound healing assays, and western blotting. Dual-luciferase reporter assays were performed to confirm the correlated between NEAT and miR-1321, miR-1321 and TJP3. The effect of NEAT1 on miR-1321 and TJP3 was confirmed by RT-qPCR and western blotting. Elevated expression of NEAT1 was observed in OC cell lines, and NEAT1 expression was found to be positively related to the expression of tight junction protein 3 (TJP3), which is important in cancer development. Moreover, the present results indicated that NEAT1 and TJP3 expression levels were negatively correlated with microRNA (miR)-1321 expression in OC. Knockdown of NEAT1 attenuated the migration and invasion of OC cells, as well as increased miR-1321 expression and in turn led to the reduction of TJP3. Thus, the present study demonstrated that NEAT1 regulates TJP3 expression by sponging miR-1321 and enhances the
\end{abstract}

Correspondence to: Professor Chen Qing, School of Pharmaceutical Sciences and Yunnan Key Laboratory of Pharmacology for Natural Products, Kunming Medical University, 1168 West Chunrong Road, Yuhua, Chenggong, Kunming, Yunnan 650500, P.R. China

E-mail: qingchenhh@yeah.net

Key words: ovarian cancer, long non-coding RNA, nuclear enriched abundant transcript 1, microRNA-1321, tight junction protein 3 epithelial-mesenchymal transition, invasion and migration of OC cells. Overall, the present study identified the function and mechanism of NEAT1 in OC, suggesting that NEAT1 may be a promising therapeutic target for OC metastasis.

\section{Introduction}

Ovarian cancer (OC) is a major malignant tumor of the female reproductive system and has a high mortality rate. A study demonstrated that $47 \%$ of women diagnosed with ovarian cancer survive five years after diagnosis worldwide (1). As the early symptoms are not obvious, the disease onset is hidden and metastasis occurs earlier, which poses a great threat to women's health (2). The invasion and metastasis of $\mathrm{OC}$ is a multifactor and multistep process that is regulated by multiple factors such as IncRNA PTAR (3), and miR-320 (4) and oncoprotein Rab23 (5). However, currently, the molecular mechanisms are not completely elucidated.

Long non-coding (lnc.) RNAs are non-coding RNAs with specific sequences $>200$ nucleotides in length, which are conserved during mammalian evolution $(6,7)$. Previous studies have reported that IncRNAs participate in several biological processes, such as proliferation (8), metabolism (9) and metastasis (10). Moreover, lncRNAs, such as HOTTIP (11), DNM3OS (12) and PTAR (3), are suggested to have a vital role in the development and progression of OC. LncRNA nuclear enriched abundant transcript 1 (NEAT1) has been revealed to be dysregulated in various human cancer types, such as cervical cancer (13), breast cancer (14) and melanoma (15). Inhibition of NEAT1 is known to attenuate the proliferation, migration and invasion of melanoma cells (16); for example, a study has previously shown that NEAT1 is upregulated in papillary thyroid carcinoma tissues and cell lines, and can promote proliferation, invasion and migration (17). However, the function of NEAT1 in OC is currently unknown.

Epithelial-mesenchymal transition (EMT) is a unique biological process, which refers to the process of transforming polar epithelial cells into mesenchymal cells with mobility (18). From the perspective of molecular biology, 
EMT mainly involves the downregulated expression of epithelial cell markers, E-cadherin and $\beta$-catenin, and the upregulated expression of the interstitial cell markers, fibronectin and Vimentin (19). In recent years, the relationship between IncRNA and tumor EMT has been widely reported, and numerous IncRNAs have been shown to promote the EMT process via different molecular mechanisms in several tumors. For instance, lncRNA SNHG5 induces zinc finger E-box binding homeobox 1 expression by competitively inhibiting microRNA (miRNA/miR)-205-5p, thus promoting the EMT process in clear cell renal cell carcinoma (20). Furthermore, IncRNA AFAP1-AS1 promotes the EMT process of liver cancer by acting on the oncogenic protein CRKL-mediated Ras/mitogen-activated protein kinase kinase/c-Jun and the cadherin/vimentin signaling pathway (21), while lncRNA ROR1-AS1 promotes the EMT process of cervical cancer via the Wnt/ $\beta$-catenin pathway (22).

The role of miRNA in the progression of carcinogenesis has been well characterized $(23,24)$. Previous studies have reported that IncRNAs can regulate the expression of miRNAs as competitive endogenous RNAs (25). For example, HOXD-AS1 was found to inhibit the expression of miR-133a-3p and subsequently enhance the EMT process of OC (26), while lncRNA H19 was determined to be an endogenous competitive RNA that inhibits miR-370-3p expression and further promotes the EMT process (27). However, to the best of our knowledge, there are currently no reports as to whether NEAT1 affects the biological features of OC cells via miRNA.

A study suggested that more than $90 \%$ of malignant ovarian tumors are of epithelial origin (28). Tight junction protein 3 (TJP3), also named ZO-3, is a scaffolding protein (29) that has a significant role in intercellular communication (30) and epithelial differentiation (31). Thus, we hypothesized that TJP3 plays a crucial role in OC. In fact, the role of TJP3 in tumor progression has been clarified. TJP3 is required for 4-(furan-2-yl)-2-(pyridin-2-yl)-5, 6-dihydro-1, 10-phenanthroline (FPDHP)-regulated cancer therapy (32). In prostate cancer, hepatocyte growth factor (HGF) modulates metastasis through TJ proteins including TJP3 (33). TJP3 is proposed as a diagnostic tool for lung cancer (34) and is associated with poor prognosis in patients with breast cancer (35). Moreover, in endometrial cancer, TJP3 functions as a molecular marker (36). However, the potential role of TJP3 in the progression of OC remains unknown.

Previous studies demonstrated lncRNA NEAT1 has an important significance on OC $(37,38)$. Bioinformatics analysis indicated miR-1321 is a target of NEAT. It has been reported that Cordyceps militaris could reduce the severity of acute lung injury in mice via miR-1321- and miR-3188-mediated C-X-C motif chemokine receptor 2 inhibition (39). miR-1321 was also revealed to be abnormally expressed in pediatric glioma using miRNA microarray analysis (40). Based on the aforementioned findings, it was hypothesized that miR-1321 has an important role in the process of cancer development. In this study, the role of NEAT1 in OC cell invasion and metastasis were well characterized. This study also demonstrated the underlying mechanism by which NEAT1 modulates OC cell invasion and metastasis.

\section{Materials and methods}

Specimens collection. Surgical samples (tumor tissues and matched adjacent healthy tissues) were collected from 36 female patients with ovarian cancer from 05/2018-02/2019 in Department of Gynecology, Yunnan Tumor Hospital \& The Third Affiliated Hospital of Kunming Medical University. The age range age of patients was 25-65 years old with an average age of $42.56 \pm 12.12$ years old. All specimen diagnoses were confirmed by a qualified pathologist after surgery. The study was approved by the Research Ethics Committee of Kunming Medical University and written informed consent was obtained from each patient.

Cell culture. The epithelial normal cell line (IOSE80) and four OC cell lines (OVCAR-3, SKOV3, ES-2 and A2780) were purchased from American Type Culture Collection. 293T cells was purchased from Thermo Fisher Scientific, Inc. All the cell lines were cultured in DMEM (cat. no. 12100; Beijing Solarbio Science \& Technology Co., Ltd.) supplemented with 10\% FBS (cat. no. 11041-8611; Beijing Solarbio Science \& Technology Co., Ltd.), $100 \mu \mathrm{g} / \mathrm{ml}$ streptomycin and $100 \mathrm{IU} / \mathrm{ml}$ penicillin at $37^{\circ} \mathrm{C}$ in a $5 \% \mathrm{CO}_{2}$ chamber.

Reverse transcription-quantitative PCR (RT-qPCR) analysis. Total RNA was isolated from the OC cells using TRIzol ${ }^{\circledR}$ reagent (cat. no. 15596026; Invitrogen; Thermo Fisher Scientific, Inc.). $0.5 \mu \mathrm{g}$ total RNA was reverse transcribed to cDNA via PrimeScript ${ }^{\mathrm{TM}}$ RT Master Mix (cat. no. RR036A; Takara Bio, Inc.). The cDNA was diluted 1:10. The reaction conditions were as follows: 6 cycles of $15 \mathrm{~min}$ at $37^{\circ} \mathrm{C}, 85^{\circ} \mathrm{C}$ for $5 \mathrm{sec}$. The detection of NEAT1 expression was achieved using SYBR $^{\circledR}$ Premix Ex Taq ${ }^{\mathrm{TM}}$ II kit (cat. no. RR820A; Takara Bio, Inc.) with the LightCycler ${ }^{\circledR} 96$ instrument (Roche Diagnostics). GAPDH was used as an internal control to standardize the results. The reaction conditions were as follows: $95^{\circ} \mathrm{C}$ for $30 \mathrm{sec} ; 40$ cycles of $5 \mathrm{sec}$ at $95^{\circ} \mathrm{C}, 30 \mathrm{sec}$ at $60^{\circ} \mathrm{C}$ and $15 \mathrm{sec}$ at $65^{\circ} \mathrm{C}$, and $10 \mathrm{~min}$ at $72^{\circ} \mathrm{C}$. The sequences of the specific primers are as follows: 1ncRNA NEAT1 forward, 5'-TCGGGTATG CTGTTGTGAAA-3' and reverse, 5'-TGACGTAACAGAATT AGTTCTTACCA-3'; and GAPDH forward, 5'-GGTCTCCTC TGACTTCAACA-3' and reverse, 5'-GTGAGGGTCTCTCTC TTCCT-3'. miR-1321 forward, 5'-GCGGCGGCAGGGAGG TGAATGTG-3' and reverse, 5'- ATCCAGTGCAGGGTCCGA GG-3'; U6 forward, 5'-CTCGCTTCGGCAGCACA-3' and reverse, 5'-GCAGGGTCCGAGGTATTC-3'. The PureLink ${ }^{\mathrm{TM}}$ miRNA Isolation kit (cat. no. K157001; Invitrogen; Thermo Fisher Scientific, Inc.) was used for miR-1321 acquisition, and the quantification of miRNA expression was performed with a TaqMan MicroRNA Assay kit (cat. no. 4366593; Applied Biosystems; Thermo Fisher Scientific, Inc.). The expression was measured using the $2^{-\Delta \Delta \mathrm{Cq}}$ method (41).

Western blotting. OC cell lysates were harvested using RIPA lysis buffer (cat. no. R0010; Beijing Solarbio Science \& Technology Co., Ltd.). The protein concentrations were determined using a bicinchoninic acid kit (cat. no. P0012, Beyotime Institute of Biotechnology) and $20 \mu \mathrm{g}$ proteins were loaded in to each well. Proteins were separated using $10 \%$ SDS-PAGE and transferred to PVDF membranes 
(cat. no. IPVH00010; Merck KGaA). The membranes were blocked with $10 \%$ milk at room temperature for $1 \mathrm{~h}$. Cells were blotted with specific primary antibodies against E-cadherin (1:3,000; cat. no. ab15148; Abcam), N-cadherin (1:3,000; cat. no. ab18203; Abcam), vimentin (1:3,000; cat. no. ab11256; Abcam), TJP3 (1:2,000; cat. no. 710857; Thermo Fisher Scientific, Inc.) or GAPDH (1:3,000; cat. no. ab9485; Abcam) at $4{ }^{\circ} \mathrm{C}$ overnight and then incubated with a horseradish peroxide-conjugated goat anti-rabbit IgG $\mathrm{H} \& \mathrm{~L}$ secondary antibody (1:10,000; cat. no. ab205718; Abcam) for $1 \mathrm{~h}$ at room temperature. The signal of proteins was visualized using ECL detection reagent (cat. no. 36208ES60, Shanghai Yeasen Biotechnology Co., Ltd.) with a Tanon-5200 imaging system (Tanon Science \& Technology Co., Ltd.). ImageJ 1.8.0 software (National Institutes of Health) was used to quantify the western blots.

Cell transfection. The small interfering (si)RNA, specifically targeting the lncRNA NEAT1 (si-NEAT1; sense: 5'-AGUUUA GCGCCAAACCUAGAG-3'; antisense: 5'-CUAGGUUUG GCGCUAAACUCU-3'), and TJP3 (si-TJP3; sense: 5'-AAU UAGCUGGGCAUAGUGGUG-3'; antisense: 5'-CCACUA UGCCCAGCUAAUUUU-3') were obtained from RiboBio. miR-1321 mimics and the pcDNA-TJP3 overexpression plasmid (OE-TJP3) were constructed by Cytiva. Cells were plated on 6 -well plates $\left(2 \times 10^{5}\right.$ cells/well $)$. Plasmids $(2 \mu \mathrm{g})$ and siRNAs $(1.5 \mu \mathrm{g})$ were diluted in $50 \mu \mathrm{l}$ medium with $1 \mu$ l Lipofectamine ${ }^{\circledR} 2000$ (cat. no. 11668-027; Invitrogen; Thermo Fisher Scientific, Inc.) according to the manufacturer's protocol. The mixture was added to the wells after $15 \mathrm{~min}$. Cells were co-cultured with the plasmid and/or siRNA and Lipofectamine ${ }^{\circledR} 2000$ mixture for $24 \mathrm{~h}$ in a humidified $5 \% \mathrm{CO}_{2}$ incubator at $37^{\circ} \mathrm{C}$ and then replaced with complete medium containing $10 \%$ FBS.

Cell proliferation assays. Transfected cells and their corresponding controls were cultured in 96-well plates $\left(2 \times 10^{3}\right.$ cells/well). Proliferation was assessed using the Cell Counting Kit-8 assay (CCK-8; Beyotime Institute of Biotechnology) at $0,24,48,72$ and $96 \mathrm{~h}$ according to the manufacturer's protocol. The absorbance at $450 \mathrm{~nm}$ was detected with a microplate reader (Bio-Rad Laboratories Inc.).

Transwell assays. Transwell assays were performed using Millipore Transwell chambers $(8-\mu \mathrm{m}$ pore size; cat. no. MCEP06H48; EMD Millipore). Transfected ES-2 and A2780 cells $\left(2 \times 10^{4}\right.$ cells/well $)$ were seeded in the upper chambers of a 12-well plate (Corning, Inc.) in $500 \mu \mathrm{l}$ serum-free medium with $500 \mu$ l complete medium added to the bottom chamber. The chamber was incubated for $24 \mathrm{~h}$ in a humidified $5 \% \mathrm{CO}_{2}$ incubator at $37^{\circ} \mathrm{C}$. At the end of incubation, cotton-tipped swabs were used to remove the non-migratory and non-invading cells. For invasion assays, the upper chamber was precoated with Matrigel (EMD Millipore) for $30 \mathrm{~min}$ at $37^{\circ} \mathrm{C}$. Then, the remaining cells were fixed with formaldehyde and stained using $0.1 \%$ crystal violet at $37^{\circ} \mathrm{C}$ for $1 \mathrm{~h}$. The images were captured using an Olympus CKX31 inverted microscope (Olympus Corporation) at x100 magnification and quantified by ImageJ 1.8.0 software (National Institutes of Health).
Wound-healing assays. Transfected ES-2 and A2780 cells and their corresponding controls (cell density of $3 \times 10^{5} / \mathrm{ml}$ ) were cultured in 6-well plates (Sigma-Aldrich; Merck KGaA) in DMEM supplemented with $10 \% \mathrm{FBS}$, overnight to form a confluent monolayer. The $500 \mu \mathrm{m}$ scratch was performed on this monolayer with a 1-ml pipette tip under sterile conditions and then the cells were washed twice with serum-free culture media. The cells were allowed to migrate freely across the scratch. Images were captured with a digital camera (Canon, Inc.) after $24 \mathrm{~h}$. Marks were made at the bottom of the dish to ensure that all images were captured at the same site. The area within the scratch occupied by cells was taken at 0 and $24 \mathrm{~h}$ under an inverted microscope (Olympus) at X100 magnification and calculated with ImageJ 1.8.0 software (National Institutes of Health). The percentage of gap closure was used as an indicator of cell migration.

Dual-luciferase reporter assays. The bioinformatics prediction website starBase (http://starbase.sysu.edu.cn) $(42,43)$ was used to predict the complementary binding sites between NEAT1 or TJP3 and miR-1321. A fragment of the wild-type (WT) and mutated (MUT) 3'-untranslated region (UTR) NEAT1 or TJP3 containing the predicted miR-1321 targeting regions was amplified (Guangzhou FulenGen Co. Ltd.) and cloned into the pGL3-reporter luciferase reporter vector (Sigma-Aldrich; Merck KGaA) at Kpn I and Hind III restriction sites or Hind III and Xho I restriction sites by PCR. The PCR thermocycling protocol was as follows: $98^{\circ} \mathrm{C}$ for $3 \mathrm{~min} ; 30$ cycles of $30 \mathrm{sec}$ at $98^{\circ} \mathrm{C}, 30 \mathrm{sec}$ at $57^{\circ} \mathrm{C}$ and $3 \mathrm{~min}$ at $72^{\circ} \mathrm{C} ; 10 \mathrm{~min}$ at $72^{\circ} \mathrm{C}$. The PCR sequences were as follows: NEAT1 forward, 5'-TCGACA CCССТTCTTCСТCССTT-3' and reverse, 3'-AGCTAAGGG AGGAAGAAGGGGTG-5', TJP3 forward, 5'-TCGACCCAC AACCTTACCTCCCTC-3' and reverse, 3'-AGCTGAGGG AGGTAAGGTTGTGGG-5'.

293 T cells (Thermo Fisher Scientific, Inc.) were co-transfected with either $20 \mathrm{nM}$ TJP3-3'UTR-wt or TJP3-3'UTR-mut with miR-1321 mimic or negative control (NC) mimics using Lipofectamine ${ }^{\circledR} 2000$ (Invitrogen; Thermo Fisher Scientific, Inc.) and incubated at $37^{\circ} \mathrm{C}$ in a $5 \% \mathrm{CO}_{2}$ chamber for $48 \mathrm{~h}$. the luciferase activity of the harvested cells was measured by Dual-Luciferase Assay reagent (Promega Corporation) according to the manufacturer's protocol. Renilla luciferase was normalized to firefly luciferase activity.

Statistical analysis. Data are presented as the mean \pm standard deviation of $\geq 3$ independent repeats. Unpaired Student's t-test was used to analyze the differences between the two groups. One-way ANOVA with Tukey's post hoc test was used to analyze the differences between multiple groups. A Pearson correlation coefficient test was used to detect the relationship between lncRNA NEAT1, miR-1321 and TJP3. P<0.05 was considered to indicate a statistically significant difference.

\section{Results}

lncRNA NEAT1 expression and function in OC. NEAT1 expression in normal epithelial cells (IOSE80) and four OC cell lines (SKOV3, OVCAR-3, ES-2 and A2780) was measured by RT-qPCR. NEAT1 was highly expressed in OC 
cells, especially in ES-2 and A2780 cells (P<0.05; Fig. 1A). Therefore, ES-2 and A2780 were selected for the subsequent experiments.

The function of NEAT1 in OC cells was subsequently analyzed via NEAT1 knockdown in ES-2 and A2780 cells. NEAT1 expression was successfully depleted in ES-2 and A2780 cells transfected with si-NEAT1 compared with the NC group $(\mathrm{P}<0.05$; Fig. 1B). CCK-8 results demonstrated that cell proliferation was decreased following downregulation of NEAT1 (P<0.05; Fig. 1C). Moreover, it was found that NEAT1 knockdown led to the upregulation of the E-cadherin protein and downregulation of $\mathrm{N}$-cadherin and vimentin expression levels $(\mathrm{P}<0.05$; Fig. 1D), which in turn, suggested that NEAT1 inhibition attenuated cell metastasis. Transwell assays and wound-healing assays also indicated that NEAT1 knockdown significantly reduced the migratory and invasive abilities of OC cells $(\mathrm{P}<0.05$; Fig. 1E and F). These results demonstrated that NEAT1 may serve a regulatory role in cell EMT, as well as the migratory and invasive potential of OC.

Interrelation of IncRNA NEAT1, miR-1321 and TJP3. The present study found that NEAT1 and miR-1321 had complementary base sequences using the bioinformatics prediction website starBase (Fig. 2A). miR-1321 has been shown to be related to cancer genesis (40), but the function of miR-1321 in cancer remains unknown. To assess the relationship between NEAT1 and miR-1321, a dual-luciferase reporter assay was performed after the transfection efficiency of the miR-1321 mimics was verified $(\mathrm{P}<0.05$; Fig. $2 \mathrm{~B})$. It was demonstrated that luciferase activity was decreased in 293T cells co-transfected with NEAT1 WT and miR-1321 mimics $(\mathrm{P}<0.05$; Fig. $2 \mathrm{C})$, while there was no change in NEAT1 MUT. The target genes of miR-1321 were also investigated using starBase (Fig. 2D), and TJP3 was found to be a target gene of miR-1321. Furthermore, the results indicated that transfection with miR-1321 mimics decreased the luciferase activity of TJP3 WT ( $<<0.05$; Fig. 2E) but did not influence the luciferase activity of TJP3 MUT.

RT-qPCR results demonstrated that miR-1321 expression was downregulated in ES-2 and A2780 cells ( $\mathrm{P}<0.05$; Fig. 2F). Then, the relationship between IncRNA NEAT1, miR-1321 and TJP3 was analyzed. The results identified that miR-1321 expression was upregulated in ES-2 and A2780 cells following knockdown of NEAT1 (P<0.01; Fig. 2G). Furthermore, transfection with an miR-1321 mimic led to the downregulation of TJP3 protein expression in ES-2 and A2780 cells $(\mathrm{P}<0.01$; Fig. 2H).

Pearson's correlation analysis was conducted to assess the relationship between NEAT1, miR-1321 and TJP3 in OC specimens. The results demonstrated a weak negative correlation between miR-1321 and NEAT1 expression levels, as well as between miR-1321 and TJP3 (Fig. 2I and J), and a weak positive correlation between NEAT1 and TJP3 (Fig. 2K). The aforementioned findings indicated that NEAT1 regulated TJP3 expression by sponging miR-1321.

TJP3 expression and function in OC. To determine the role of TJP3 in OC, the expression of TJP3 was first detected in normal epithelial cells (IOSE80) and OC cells (ES-2 and A2780). The protein expression of TJP3 was enhanced in
ES-2 and A2780 cells compared with IOSE80 cells ( $\mathrm{P}<0.05$; Fig. 3A). Then, ES-2 and A2780 cells were transfected with si-TJP3. The results demonstrated that, compared with the NC group, the protein expression of TJP3 was decreased following si-TJP3 transfection in ES-2 and A2780 cells $(\mathrm{P}<0.05$; Fig. 3B). In addition, TJP3 knockdown led to a reduction in the cell proliferation compared with the $\mathrm{NC}(\mathrm{P}<0.05$; Fig. $3 \mathrm{C})$. The protein expression of the EMT marker E-cadherin was increased after knockdown of TJP3, but the protein expression levels of N-cadherin and vimentin were decreased in both ES-2 and A2780 cells ( $\mathrm{P}<0.05$; Fig. 3D). In addition, Transwell and wound-healing assays indicated that the migratory and invasive abilities of ES-2 and A2780 cells were reduced following the knockdown of TJP3 ( $\mathrm{P}<0.05$; Fig. 3E and F). These findings suggested that TJP3 regulated the EMT, migratory and invasive potential of OC cells.

IncRNA NEATI promotes cell EMT, migration and invasion of $O C$ by regulating TJP3. To further investigate whether NEAT1-induced EMT in OC cells was mediated by TJP3, ES-2 and A2780 cells were transfected with si-NEAT1 and/or OE-TJP3. NEAT1 was downregulated in ES-2 and A2780 cells using si-NEAT1 transfection, and TJP3 was found to be overexpressed following treatment with OE-TJP3 $(\mathrm{P}<0.05$; Figs. 4A and S1).

Western blotting was used to measure the effect of NEAT1 on TJP3 expression. The results identified that protein expression of TJP3 was significantly decreased by knocking down NEAT1 in ES-2 and A2780 cells; however, the inhibitory effect was alleviated by overexpression of TJP3 $(\mathrm{P}<0.05$; Fig. 4B). Cell proliferative abilities were also decreased by NEAT1 knockdown, but TJP3 overexpression partly rescued the proliferative abilities of ES-2 and A2780 cells $(\mathrm{P}<0.05$; Fig. 4C). The protein expression of E-cadherin was enhanced by si-NEAT1 transfection, while the protein expression levels of $\mathrm{N}$-cadherin and vimentin were decreased $(\mathrm{P}<0.05$; Fig. 4D). However, these EMT-related protein expression levels in the si-NEAT1 + OE-TJP3 group were the same as those in the $\mathrm{NC}$ group (P $>0.05$; Fig. 4D), which indicated that NEAT1 was acting independently from TJP3 in the regulation of these EMT-related proteins. Compared with the NC group, si-NEAT1 transfection resulted in reduced cell migratory and invasive abilities according to the Transwell and wound-healing assay results. However, cell migratory and invasive abilities were significantly rescued by si-NEAT $1+$ OE-TJP $3(\mathrm{P}<0.05$; Fig. 4E and F). Therefore, the results suggested that NEAT1 promoted EMT, migration and invasion of OC cells by regulating TJP3, but also potentially via regulating proteins that are involved in cell migration and invasion, which were not included in the present study.

\section{Discussion}

The present study demonstrated that NEAT1 was highly expressed in OC cells and knockdown of NEAT1 attenuated their migratory and invasive abilities. Moreover, the present study provided evidence that NEAT1 sponges miR-1321 to enhance TJP3 protein expression, thus promoting tumor invasion and migration. The significance of the NEAT1/miR-1321/TJP3 axis in the pathogenesis of OC was 

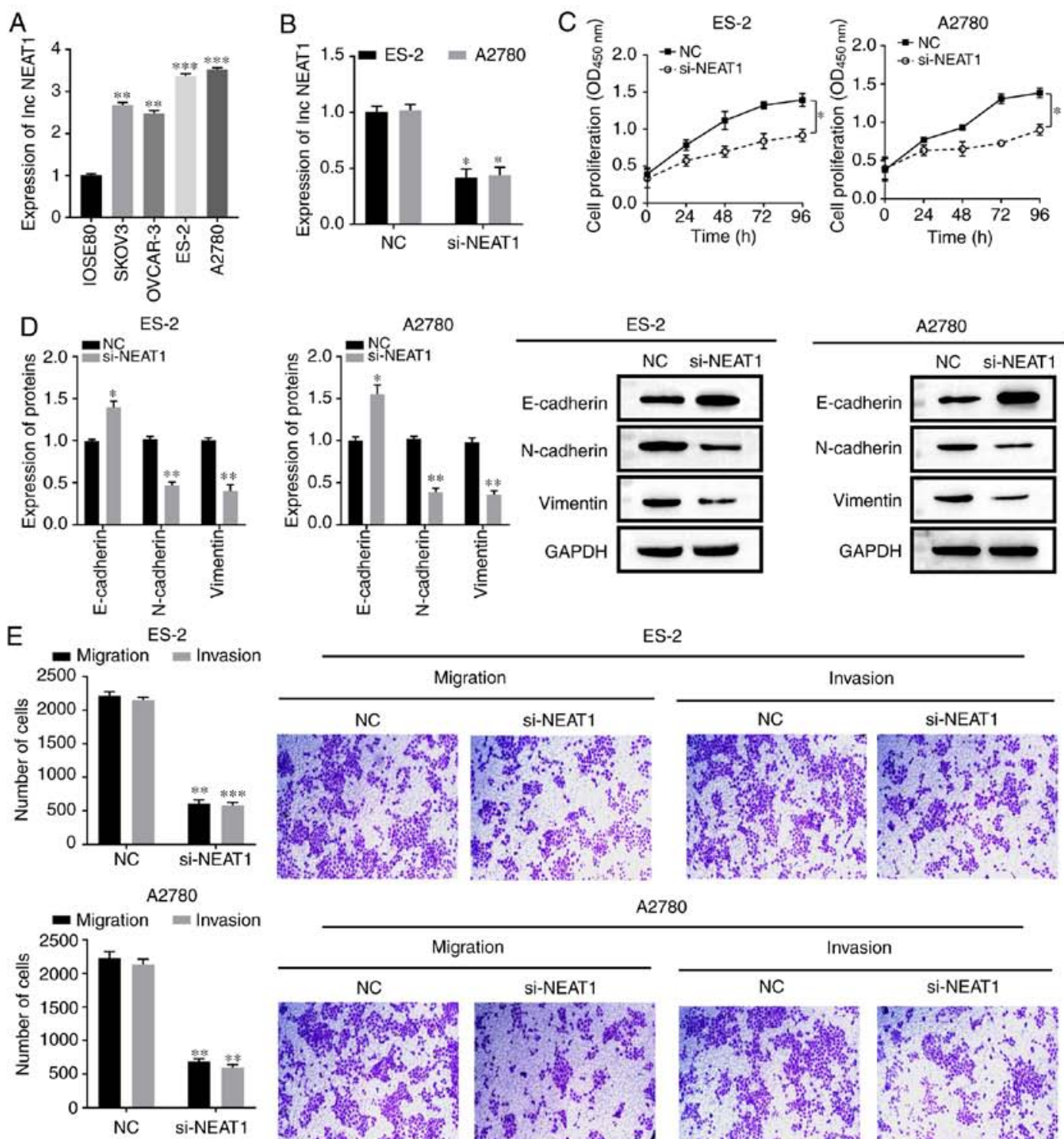

ES-2
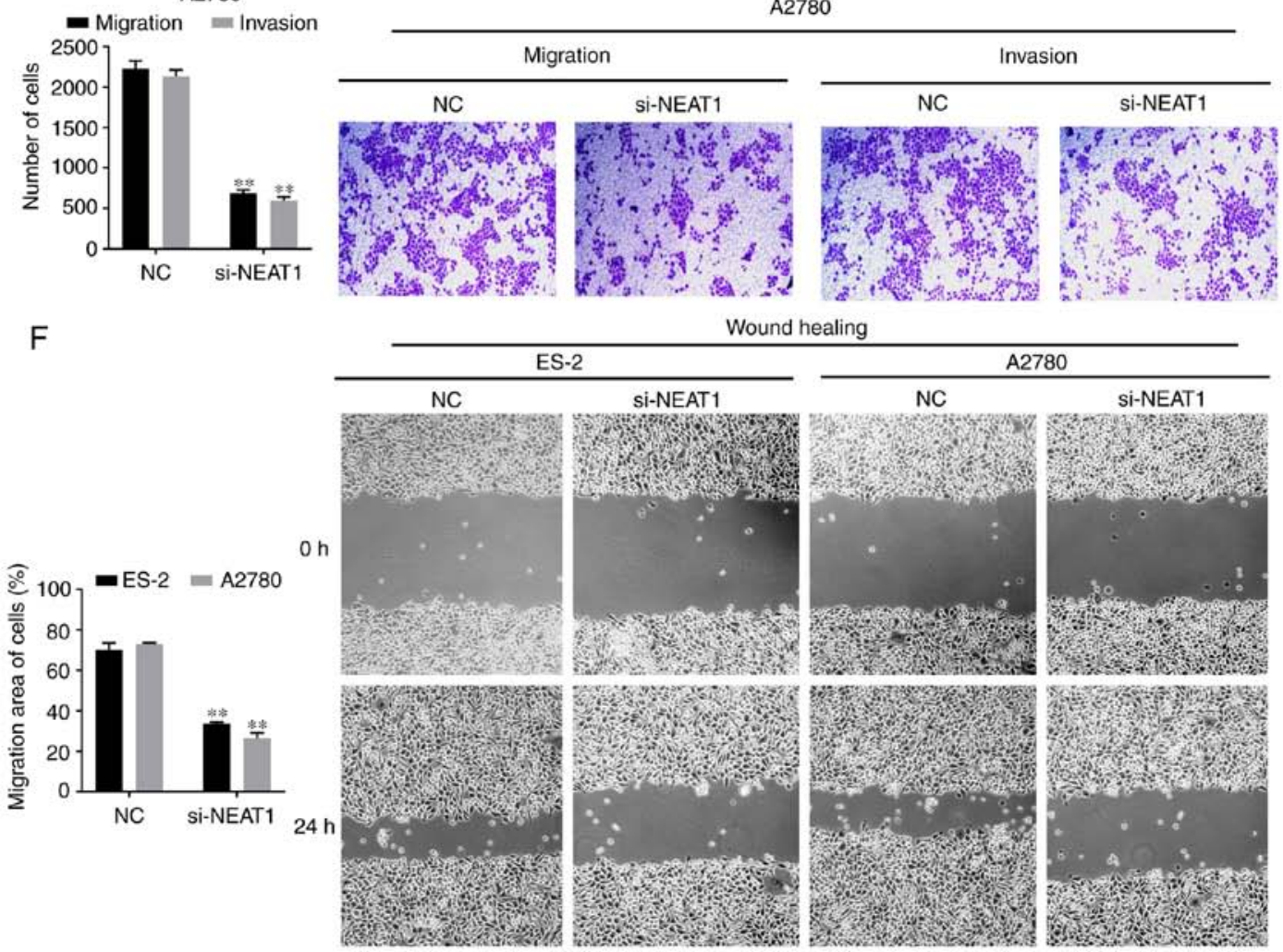

Wound healing

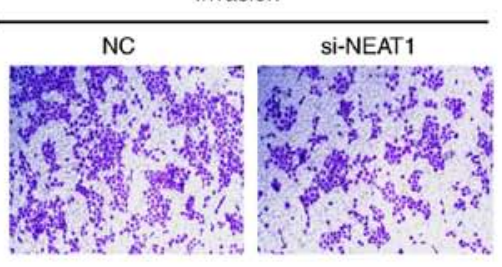

2780
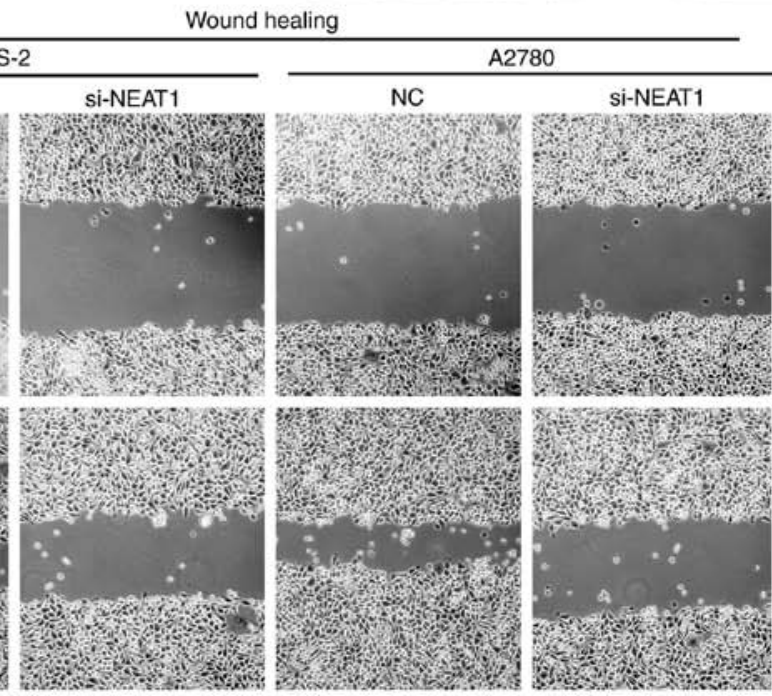

Figure 1. NEAT1 expression and function in OC. (A) NEAT1 expression in normal epithelial cells (IOSE80) and OC cells (SKOV3, OVCAR-3, ES-2 and A2780) and (B) transfection efficiency of si-NEAT1 in ES-2 and A2780 cells were detected using reverse transcription-quantitative PCR. (C) Proliferative abilities of ES-2 and A2780 cells were measured using Cell Counting Kit-8 assays. (D) E-cadherin, N-cadherin and Vimentin protein expression level in ES-2 and A2780 cells were assessed using western blotting. (E) Migration and invasive abilities of ES-2 and A2780 cells were measured using Transwell assays. Scale bar, $100 \mu \mathrm{m}$. (F) Migration abilities of ES-2 and A2780 cells were measured using wound-healing assays. Scale bar, $100 \mu \mathrm{m}$. All data are representative of $\geq 3$ independent experiments. Data are presented as the mean $\pm \mathrm{SD}$. ${ }^{*} \mathrm{P}<0.05$ vs. control group; ${ }^{* *} \mathrm{P}<0.01$ vs. control group; ${ }^{* * *} \mathrm{P}<0.001$ vs. control group, as determined by Student's t-tests or ANOVA followed by a Tukey's post hos test. OC, ovarian cancer; NEAT1, nuclear enriched abundant transcript1; si, small interfering RNA; NC, negative control; OD, optical density. 
A

Inc NEAT1-WT: 5' caCCCCUUCUUCCUCCCUu 3' miR-1321: $3^{\prime}$ uaGUGUAAG-U GGAGGGAC 5

Inc NEAT1-MUT: 5’ caGCGCAAGUUGGAGGGAu 3'

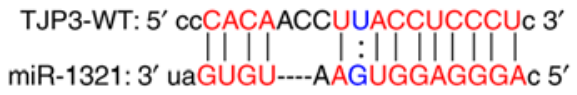

TJP3-MUT: 5' ccGUGUACCAGUGGAGGGAc 3'
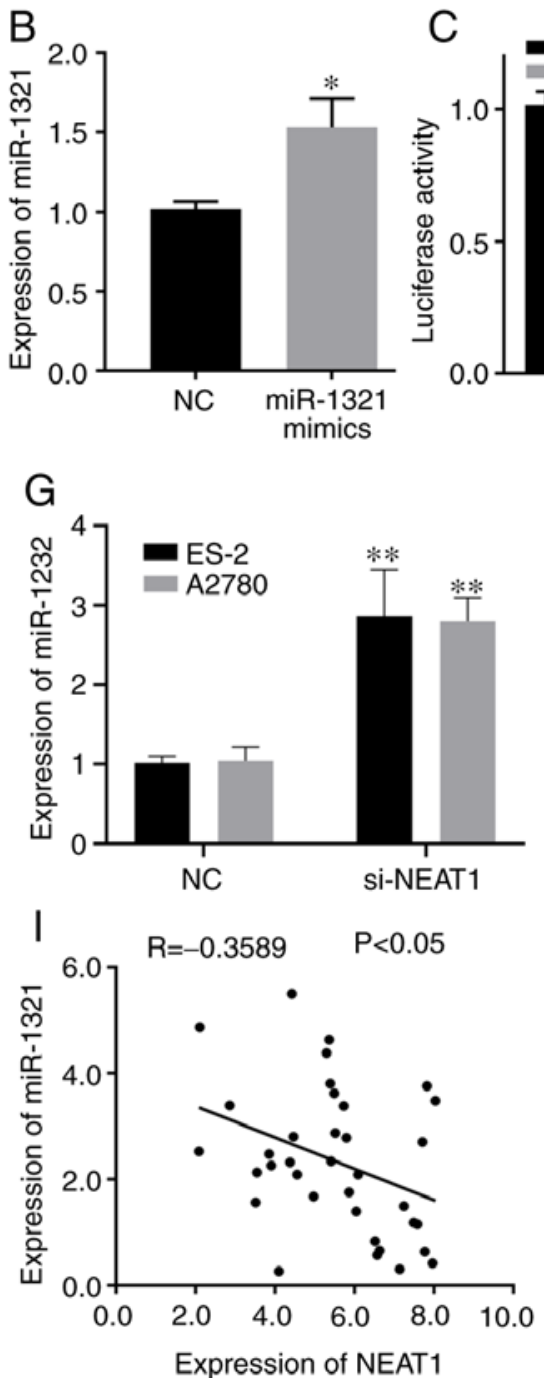
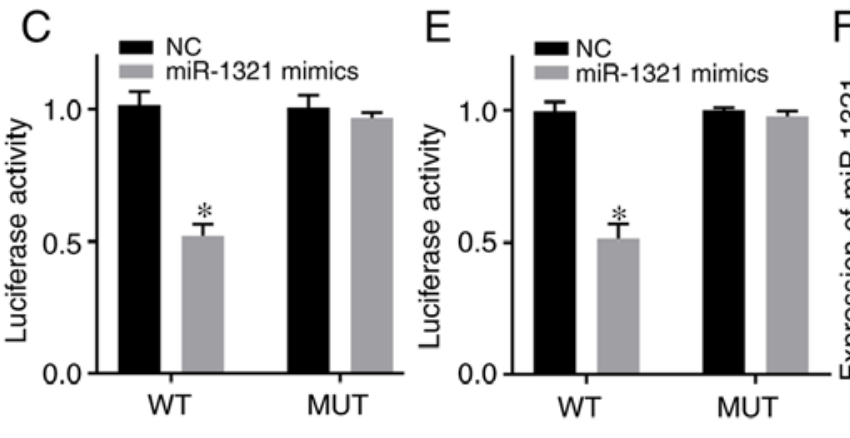

$\mathrm{F}$

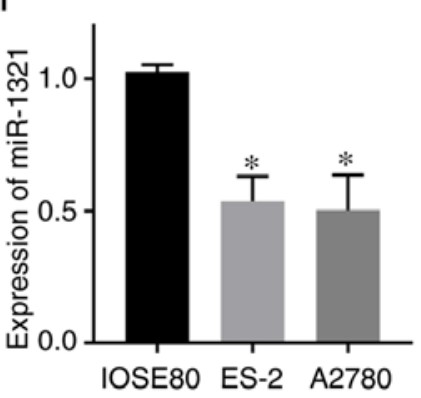

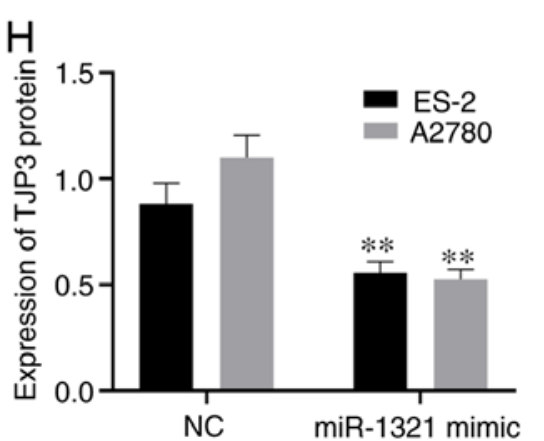

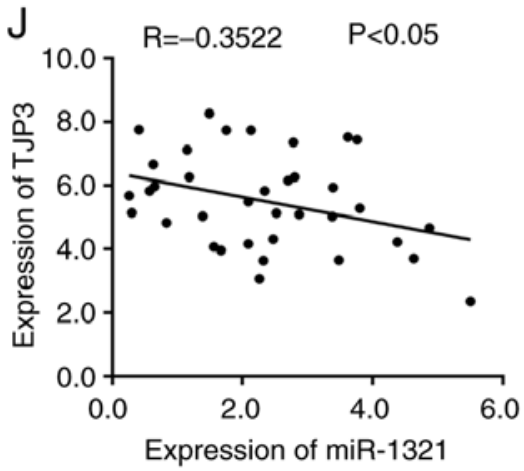

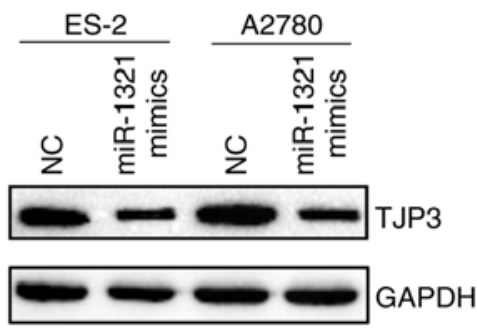

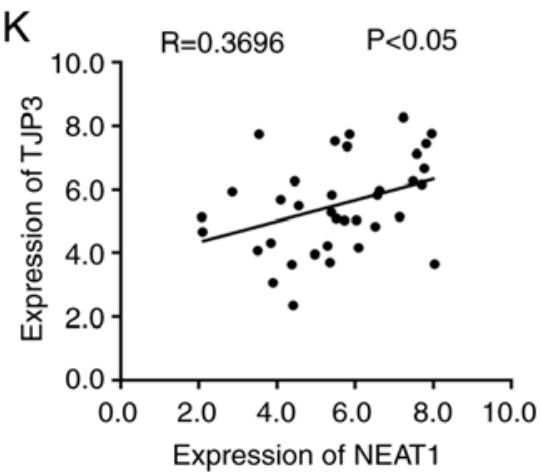

Figure 2. Interrelation of NEAT1, miR-1321 and TJP3. (A) StarBase website predicted the complementary binding sites between NEAT1 and miR-1321. (B) Transfection efficiency of miR-1321 mimics was detected using RT-qPCR. (C) Targeting relationship of NEAT1 and miR-1321 was identified using dual-luciferase reporter gene assays. (D) StarBase website predicted the complementary binding site between miR-1321 and TJP3. (E) Targeting relationship of miR-1321 and TJP3 was identified using dual-luciferase reporter gene assays. (F) Expression of miR-1321 in ES-2 and A2780 cells was measured using RT-qPCR. (G) Effect of NEAT1 on miR-1321 expression was determined using RT-qPCR. (H) Effect of miR-1321 on expression of TJP3 protein was measured using western blotting. Correlations of (I) lncRNA NEAT1 and miR-1321, (J) miR-1321 and TJP3, and (K) lncRNA NEAT1 and TJP3 on ovarian cancer specimens were investigated using a Pearson Correlation Coefficient. Data are representative of $\geq 3$ independent experiments. Data are presented as the mean \pm SD. ${ }^{*} \mathrm{P}<0.05$ vs. control group; ${ }^{* *} \mathrm{P}<0.01$ vs. control group as determined by Student's t-tests or ANOVA followed by a Tukey's post hos test. NEAT1, nuclear enriched abundant transcript1; TJP3, tight junction protein 3; miR, microRNA; NC, negative control; RT-qPCR, reverse transcription-quantitative PCR; lncRNA, long non-coding RNA; NC, negative control; WT, wild-type; MUT, mutant; si, small interfering RNA.

also identified, which suggested the potential role of NEAT1 in OC diagnosis and treatment.

Previous studies have reported the involvement of lncRNAs in the occurrence and development of a variety of cancer types, including OC (10-12). A recent study found that knockdown of NEAT1 suppressed cell proliferation, migration and invasion of melanoma cells (15). In colorectal cancer, NEAT1 has been shown to activate Wnt/ $\beta$-catenin and promote cancer progression (44). Additionally, NEAT1 has been revealed to be responsible for tumor chemoresistance $(45,46)$. The present results identified that NEAT1 was also significantly upregulated in OC. In addition, it was found that knockdown of NEAT1 led to the inhibition of migration and invasion in OC cells.

EMT is a unique biological process that promotes the metastasis of breast cancer (47), bladder cancer (48) and OC (49). It was reported that forced upregulation of NEAT1 could induce metastasis in hepatocellular cancer types via EMT (50), while another study has shown that NEAT1 affected the migratory and invasive abilities of gastric cancer cells via EMT (51). Consistent with previous studies, the present results demonstrated that knockdown of NEAT1 had an impact on 

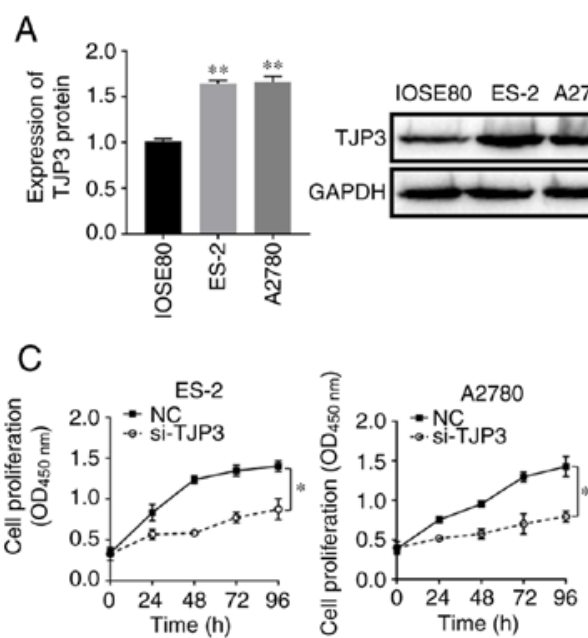

$\mathrm{D}$
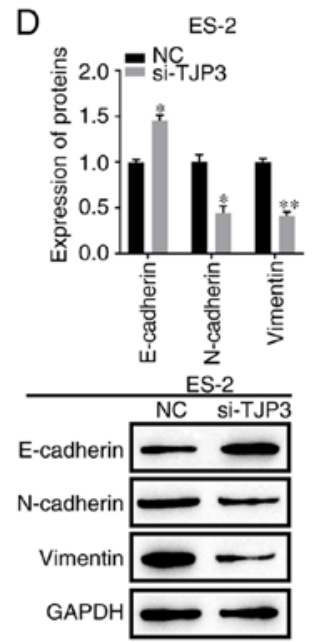

B
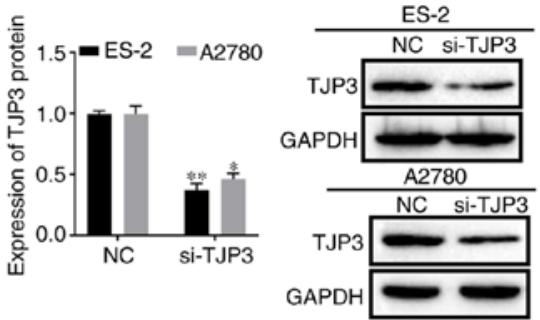

$=\mathrm{NC}^{\mathrm{A} 2780}$
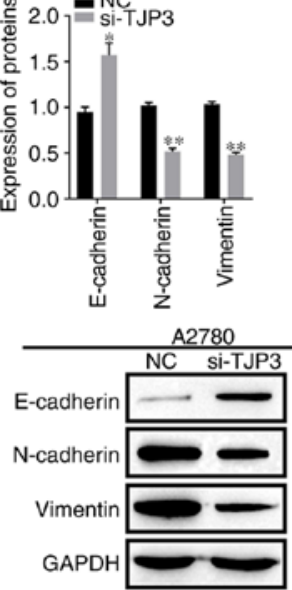

E
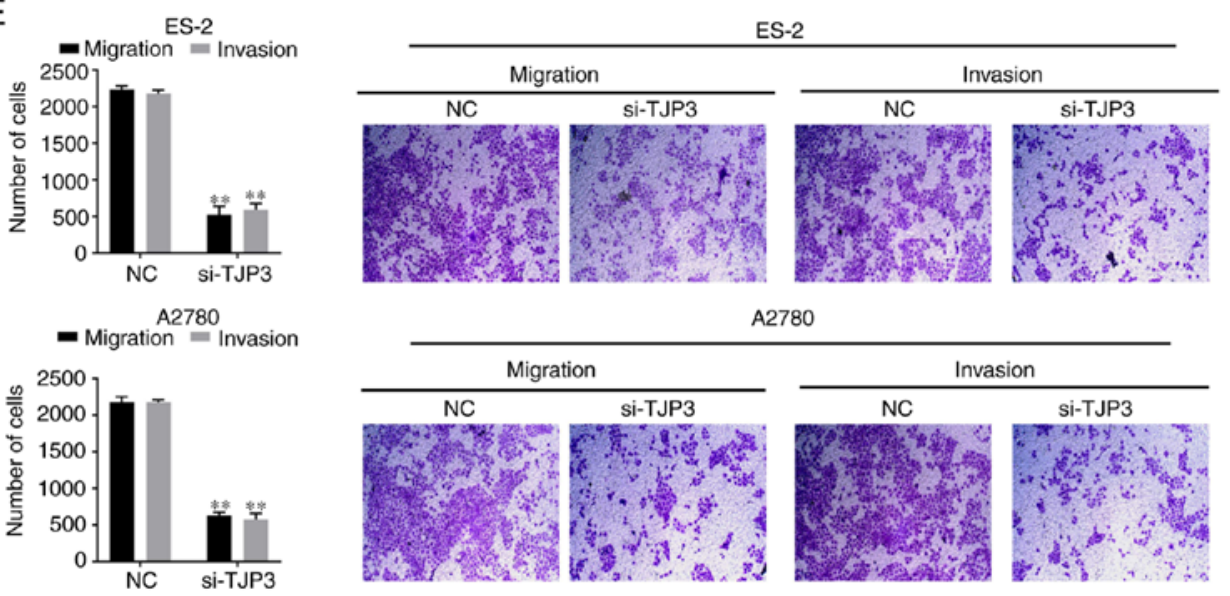

A2780
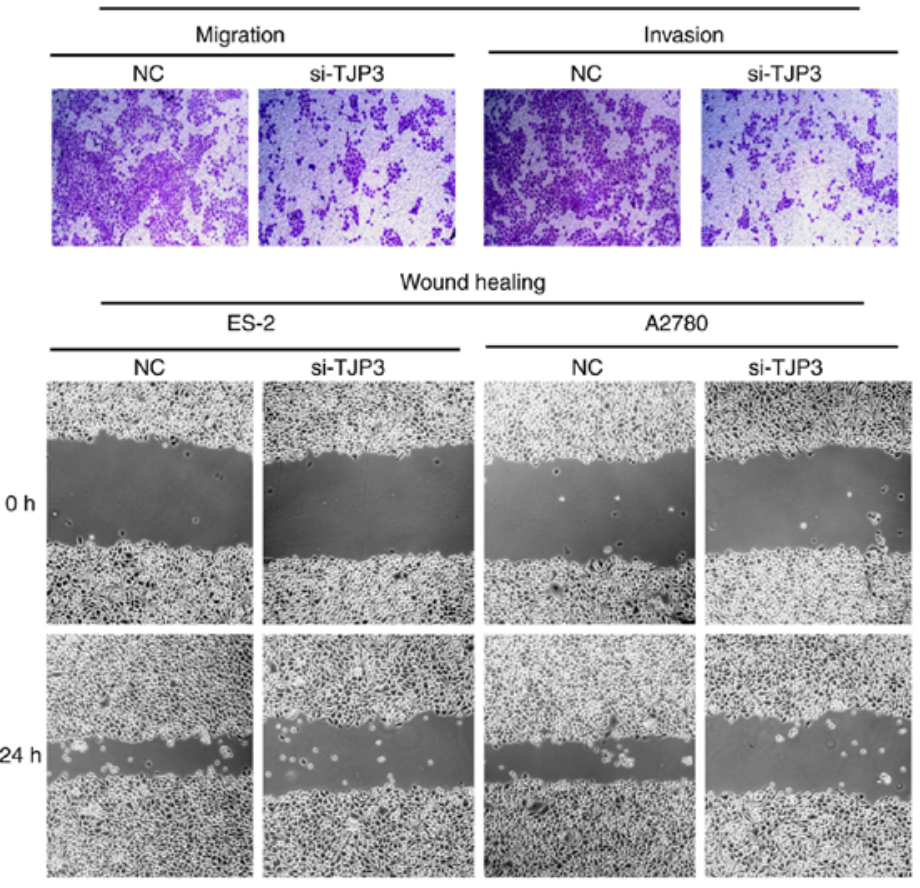

Figure 3. TJP3 expression and function in OC. (A) TJP3 protein expression level in normal epithelial cells (IOSE80) and OC cells (SKOV3, OVCAR-3, ES-2 and A2780) were measured using western blotting. (B) Transfection efficiency of si-TJP3 in ES-2 and A2780 cells were detected using western blotting. (C) Proliferative abilities of ES-2 and A2780 cells were measured using Cell Counting Kit-8 assays. (D) E-cadherin, N-cadherin and Vimentin protein expression levels in ES-2 and A2780 cells were assessed using western blotting. (E) Migratory and invasive abilities of ES-2 and A2780 cells were measured using Transwell assays. Scale bar, $100 \mu \mathrm{m}$. (F) Migratory abilities of ES-2 and A2780 cells were measured using a wound-healing assay. Scale bar, $100 \mu \mathrm{m}$. All data are representative of $\geq 3$ independent experiments. Data are presented as the mean $\pm \mathrm{SD}$. ${ }^{*} \mathrm{P}<0.05$ vs. control group; ${ }^{* *} \mathrm{P}<0.01$ vs. control group as determined by Student's t-tests or ANOVA followed by a Tukey's post hos test. TJP3, tight junction protein 3; si, small interfering RNA; NC, negative control; OC, ovarian cancer. 


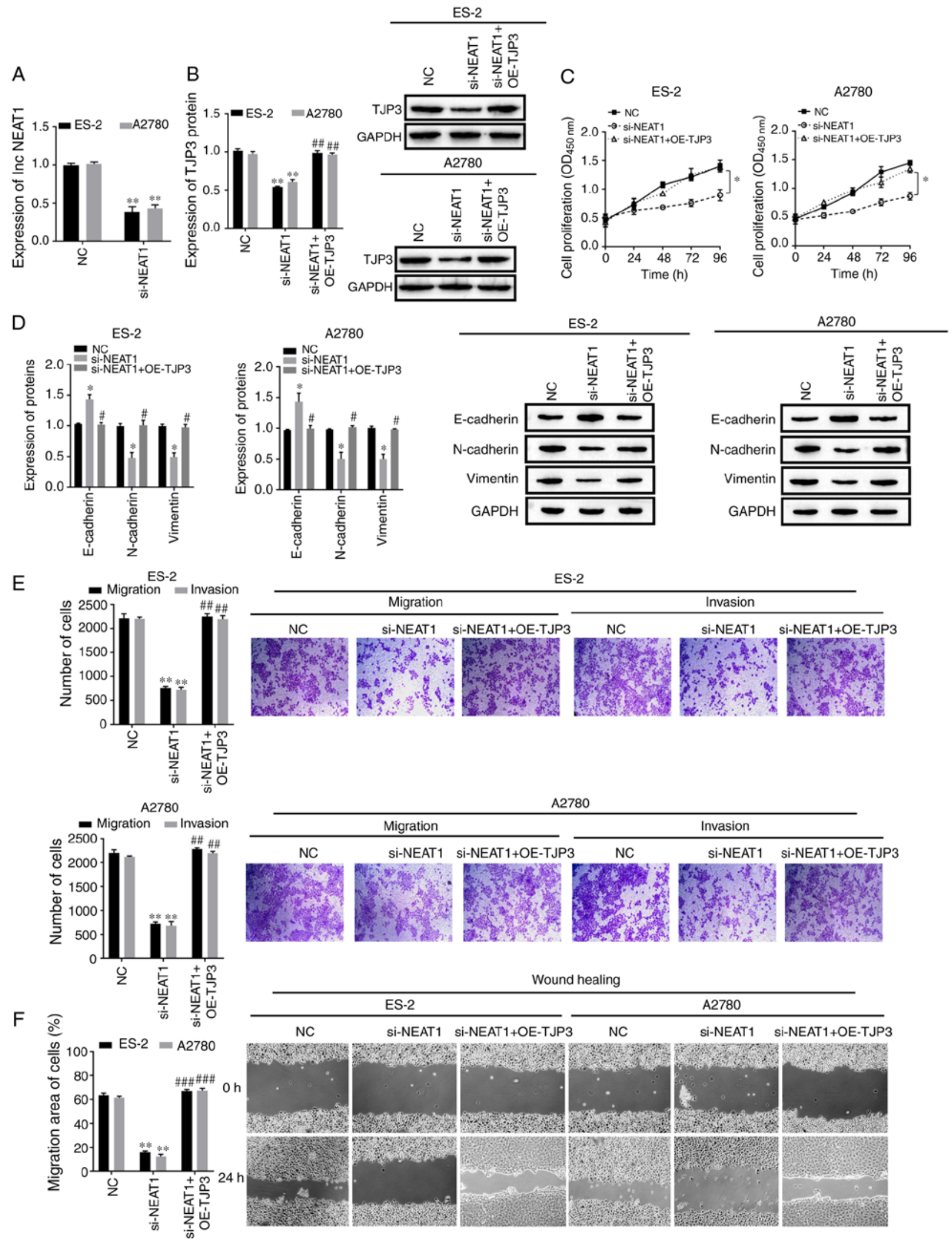

Figure 4. NEAT1 promotes cell epithelial-mesenchymal transition, migration and invasion of ovarian cancer by regulating TJP3. (A) Transfection efficiency of si-NEAT1 in ES-2 and A2780 cells were detected using reverse transcription-quantitative PCR. (B) Effect of NEAT1 on TJP3 protein expression was measured using western blotting. (C) Proliferative abilities of ES-2 and A2780 cells were measured using Cell Counting Kit-8 assays. (D) E-cadherin, N-cadherin and Vimentin protein expression levels in ES-2 and A2780 cells were assessed using western blotting. (E) Migratory and invasive abilities of ES-2 and A2780 cells were measured using Transwell assays. Scale bar, $100 \mu \mathrm{m}$. (F) Migratory abilities of ES-2 and A2780 cells were measured using a wound-healing assay. Scale bar, $100 \mu \mathrm{m}$. All data are representative of $\geq 3$ independent experiments. Data are presented as the mean \pm SD. ${ }^{*} \mathrm{P}<0.05$ vs. NC group; ${ }^{* *} \mathrm{P}<0.01$ vs. NC group; ${ }^{~} \mathrm{P}<0.05$ vs. si-NEAT1 treatment group; ${ }^{\# \#} \mathrm{P}<0.01$ vs. si-NEAT1 treatment group; ${ }^{\# \# \# ~} \mathrm{P}<0.001$ vs. si-NEAT1 treatment group as determined by Student's t-test or ANOVA followed by a Tukey's post hos test. TJP3, tight junction protein 3; NEAT1, nuclear enriched abundant transcript1; si, small interfering RNA; OE, overexpressed. 
EMT-associated proteins, including E-cadherin, vimentin and $\mathrm{N}$-cadherin, which indicated that NEAT1 regulates OC cell invasion and migration via EMT.

lncRNAs have been reported to sponge miRNAs via a competitive endogenous mechanism, thus antagonizing the function of miRNAs (52). NEAT1 upregulates Homeobox A13 by targeting miR-34a-5p and regulates the development of osteosarcoma (53). NEAT1 also promotes cervical cancer cell proliferation by sponging miR-9-5p (13). Thus, it was hypothesized that NEAT1 may act as a competitive endogenous RNA and interact with miRNAs in OC. Bioinformatic analysis and luciferase analysis were performed to screen miRNAs that directly bind to NEAT1 transcripts. NEAT1 was found to directly bind to miR-1321 and there was a mutual inhibitory effect between NEAT1 and miR-1321 in OC cells. Collectively, these data indicated that NEAT1 affects the biological characteristics of OC cells by regulating miR-1321 function.

Normal epithelial cells act as sentries in most living systems, providing a protective barrier to various organs and the surrounding environment, helping to maintain homeostasis (54). The intercellular connections of this protective barrier are divided into TJs, adhesion junctions and desmosome junctions. Among them, TJs are mainly composed of occludin, claudins and junction adhesion molecules (55). The constituent proteins of TJs participate in the modulation of intercellular communication and paracellular transport (56). Among them, TJPs, such as TJP1, 2 and 3, are framework-forming proteins that connect transmembrane proteins and the actin cytoskeleton (57). Downregulation of TJPs have been reported to be related to tumor development, such as a decrease in TJP3 expression leading to an increased capacity for migration of pancreatic cancer cells (58). A study indicated that TJP3 mRNA is upregulated in endometrial carcinoma (36). To the best of our knowledge, the present study was the first to identify that TJP3 was a direct target of miR-1321. Considering the interaction of NEAT1 and miR-1321, it was hypothesized that NEAT1 could regulate TJP3 expression in OC. As expected, the present results demonstrated that TJP3 expression was positively correlated with NEAT1 in OC cells. It was also found that TJP3 attenuated the influence of NEAT1 knockdown on OC cells. These results suggested that NEAT1 regulated TJP3 expression by interacting with miR-1321. However, in the current research, NEAT1 overexpression experiments were not performed to confirm the regulatory relationship between NEAT1 and TJP3. Therefore, further studies will be conducted to further confirm the regulation between NEAT1 and TJP3.

In conclusion, the present data suggested that NEAT1 was upregulated in OC. Thus, the current study has provided evidence that NEAT1 promotes OC cell invasion and metastasis by downregulating miR-1321 and activating TJP3 function. Therefore, the NEAT1/miR-1321/TJP3 axis may represent a new prognostic biomarker and therapeutic target in $\mathrm{OC}$.

\section{Acknowledgements}

The authors would like to thank Professor Malin Li (Yunnan University of Chinese Medicine) for her advice on this project.

\section{Funding}

The present study was funded by the National Natural Science Foundation (grant no. 81860463), the Science and Technology Department of Yunnan Province and Kunming Medical University Project Foundation [grant no. 2018FE001(-003)] and the Science and Technology Department of Yunnan Province and Kunming Medical University Project Foundation [grant no. 2017FE468(-067)].

\section{Availability of data and materials}

The datasets used and/or analyzed during the current study are available from the corresponding author on reasonable request.

\section{Authors' contributions}

CQ designed the research. ML performed the research, analyzed the data and wrote the manuscript. LZ collected clinical specimens and acquired the clinical data. HY participated in analyzing the clinical specimens data. KL perfomed the cell experiments. All authors read and approved the final manuscript.

\section{Ethics approval and consent to participate}

The study was approved by the Research Ethics Committee of Kunming Medical University and written informed consent was obtained from each patient.

\section{Patient consent for publication}

Not applicable.

\section{Competing interests}

The authors declare that they have no competing interests.

\section{References}

1. Siegel RL, Miller KD and Jemal A: Cancer statistics, 2019. CA Cancer J Clin 69: 7-34, 2019.

2. Zhao L, Wang W, Huang S, Yang Z, Xu L, Yang Q, Zhou X, Wang J, Shen Q, Wang C, et al: The RNA binding protein SORBS2 suppresses metastatic colonization of ovarian cancer by stabilizing tumor-suppressive immunomodulatory transcripts. Genome Biol 19: 35, 2018.

3. Liang H, Yu T, Han Y, Jiang H, Wang C, You T, Zhao X, Shan H, Yang R, Yang L, et al: lncRNA PTAR promotes EMT and invasion-metastasis in serous ovarian cancer by competitively binding miR-101-3p to regulate ZEB1 expression. Mol Cancer 17: 119, 2018

4. Wang W, Yang J, Xiang YY, Pi J and Bian J: Overexpression of hsa-miR-320 is associated with invasion and metastasis of ovarian cancer. J Cell Biochem 118: 3654-3661, 2017.

5. Gao L, Zheng M, Guo Q, Nie X, Li X, Hao Y, Liu J, Zhu L and Lin B: Downregulation of Rab23 inhibits proliferation, invasion, and metastasis of human ovarian cancer. Int J Biochem Cell Biol 116: 105617, 2019.

6. Zhan L, Li J and Wei B: Long non-coding RNAs in ovarian cancer. J Exp Clin Cancer Res 37: 120, 2018.

7. Bu D, Luo H, Jiao F, Fang S, Tan C, Liu Z and Zhao Y: Evolutionary annotation of conserved long non-coding RNAs in major mammalian species. Sci China Life Sci 58: 787-798, 2015. 
8. Chen QN, Chen X, Chen ZY, Nie FQ, Wei CC, Ma HW, Wan L, Yan S, Ren SN and Wang ZX: Long intergenic non-coding RNA 00152 promotes lung adenocarcinoma proliferation via interacting with EZH2 and repressing IL24 expression. Mol Cancer 16: 17, 2017.

9. Nolte W, Weikard R, Brunner RM, Albrecht E, Hammon HM, Reverter A and Kühn C: Biological network approach for the identification of regulatory long non-coding RNAs associated with metabolic efficiency in cattle. Front Genet 10: 1130, 2019.

10. Yao Z, Xiong Z, Li R, Liang H, Jia C and Deng M: Long non-coding RNA NRON is downregulated in HCC and suppresses tumour cell proliferation and metastasis. Biomed Pharmacother 104: 102-109, 2018.

11. Zou T, Wang PL, Gao Y and Liang WT: Long noncoding RNA HOTTIP is a significant indicator of ovarian cancer prognosis and enhances cell proliferation and invasion. Cancer Biomark 25: 133-139, 2019.

12. Mitra R, Chen X, Greenawalt EJ, Maulik U, Jiang W, Zhao Z and Eischen CM: Decoding critical long non-coding RNA in ovarian cancer epithelial-to-mesenchymal transition. Nat Commun 8: $1604,2017$.

13. Xie Q, Lin S, Zheng M, Cai Q and Tu Y: Long noncoding RNA NEAT1 promotes the growth of cervical cancer cells via sponging miR-9-5p. Biochem Cell Biol 97: 100-108, 2019.

14. Jiang X, Zhou Y, Sun AJ and Xue JL: NEAT1 contributes to breast cancer progression through modulating miR-448 and ZEB1. J Cell Physiol 233: 8558-8566, 2018.

15. Xia Y, Zhou Y, Han H, Li P, Wei W and Lin N: lncRNA NEAT1 facilitates melanoma cell proliferation, migration, and invasion via regulating miR-495-3p and E2F3. J Cell Physiol 234: 19592-19601, 2019.

16. Ding F, Lai J, Gao Y, Wang G, Shang J, Zhang D and Zheng S: NEAT1/miR-23a-3p/KLF3: A novel regulatory ax is in melanoma cancer progression. Cancer Cell Int 19: 217, 2019.

17. Zhang H, Cai Y, Zheng L, Zhang Z, Lin X and Jiang N: Long noncoding RNA NEAT1 regulate papillary thyroid cancer progression by modulating miR-129-5p/KLK7 expression. J Cell Physiol 233: 6638-6648, 2018

18. Aiello NM and Kang Y: Context-dependent EMT programs in cancer metastasis. J Exp Med 216: 1016-1026, 2019.

19. De Craene B and Berx G: Regulatory networks defining EMT during cancer initiation and progression. Nat Rev Cancer 13: $97-110,2013$

20. Xiang W, Lv L, Zhou G, Wu W, Yuan J, Zhang C and Jiang G: The IncRNA SNHG5-mediated miR-205-5p downregulation contributes to the progression of clear cell renal cell carcinoma by targeting ZEB1. Cancer Med 9: 4251-4264, 2020

21. Abdul S, Majid A, Wang J, Liu Q, Sun MZ and Liu S: Bidirectional interaction of lncRNA AFAP1-AS1 and CRKL accelerates the proliferative and metastatic abilities of hepatocarcinoma cells. J Adv Res 24: 121-130, 2020.

22. Zhang L, Yao HR, Liu SK and Song LL: Long noncoding RNA ROR1-AS1 overexpression predicts poor prognosis and promotes metastasis by activating Wnt/ $\beta$-catenin/EMT signaling cascade in cervical cancer. Eur Rev Med Pharmacol Sci 24: 2928-2937, 2020

23. Lai X, Eberhardt M, Schmitz U and Vera J: Systems biology-based investigation of cooperating microRNAs as monotherapy or adjuvant therapy in cancer. Nucleic Acids Res 47: 7753-7766, 2019.

24. Wilk $\mathrm{G}$ and Braun R: Integrative analysis reveals disrupted pathways regulated by microRNAs in cancer. Nucleic Acids Res 46: 1089-1101, 2018

25. Wei L, Wang X, Lv L, Liu J, Xing H, Song Y, Xie M, Lei T, Zhang $\mathrm{N}$ and Yang $\mathrm{M}$ : The emerging role of microRNAs and long noncoding RNAs in drug resistance of hepatocellular carcinoma. Mol Cancer 18: 147, 2019.

26. Zhang Y, Dun Y, Zhou S and Huang XH: lncRNA HOXD-AS1 promotes epithelial ovarian cancer cells proliferation and invasion by targeting miR-133a-3p and activating $\mathrm{Wnt} / \beta$-catenin signaling pathway. Biomed Pharmacother 96: 1216-1221, 2017.

27. Li J, Huang Y, Deng X, Luo M, Wang X, Hu H, Liu C and Zhong M: Long noncoding RNA H19 promotes transforming growth factor- $\beta$-induced epithelial-mesenchymal transition by acting as a competing endogenous RNA of miR-370-3p in ovarian cancer cells. Onco Targets Ther 11: 427-440, 2018

28. Colombo N, Sessa C, du Bois A, Ledermann J, McCluggage WG, McNeish I, Morice P, Pignata S, Ray-Coquard I, Vergote I, et al: ESMO-ESGO consensus conference recommendations on ovarian cancer: Pathology and molecular biology, early and advanced stages, borderline tumours and recurrent disease $\dagger$. Ann Oncol 30: 672-705, 2019
29. Kiener TK, Selptsova-Friedrich I and Hunziker W: Tjp3/zo-3 is critical for epidermal barrier function in zebrafish embryos. Dev Biol 316: 36-49, 2008

30. Kausalya PJ, Reichert M and Hunziker W: Connexin 45 directly binds to ZO-1 and localizes to the tight junction region in epithelial MDCK cells. FEBS Lett 505: 92-96, 2001.

31. Haskins J, Gu L, Wittchen ES, Hibbard J and Stevenson BR: ZO-3, a novel member of the MAGUK protein family found at the tight junction, interacts with ZO-1 and occludin. J Cell Biol 141: 199-208, 1998

32. Kim SG, Yooun JH, Kim DE, Lee ES, Kwon TK, Kim S and Park JW: A novel anti-cancer agent, FPDHP, induces anoikis in various human cancer cells through activation of calpain, and downregulation of anoikis-related molecules. J Cell Biochem 119: 5620-5631, 2018

33. Martin TA, Mason MD and Jiang WG: HGF and the regulation of tight junctions in human prostate cancer cells. Oncol Rep 32: 213-224, 2014.

34. Paschoud S, Bongiovanni M, Pache JC and Citi S: Claudin-1 and claudin-5 expression patterns differentiate lung squamous cell carcinomas from adenocarcinomas. Mod Pathol 20: 947-954, 2007.

35. Martin TA, Watkins G, Mansel RE and Jiang WG: Loss of tight junction plaque molecules in breast cancer tissues is associated with a poor prognosis in patients with breast cancer. Eur J Cancer 40: 2717-2725, 2004.

36. Colas E, Perez C, Cabrera S, Pedrola N, Monge M, Castellvi J, Eyzaguirre F, Gregorio J, Ruiz A, Llaurado M, et al: Molecular markers of endometrial carcinoma detected in uterine aspirates. Int J Cancer 129: 2435-2444, 2011

37. Liu Y, Wang Y, Fu X and Lu Z: Long non-coding RNA NEAT1 promoted ovarian cancer cells' metastasis through regulation of miR-382-3p/ROCK1 axial. Cancer Sci 109: 2188-2198, 2018.

38. Chen ZJ, Zhang Z, Xie BB and Zhang HY: Clinical significance of up-regulated lncRNA NEAT1 in prognosis of ovarian cancer. Eur Rev Med Pharmacol Sci 20: 3373-3377, 2016.

39. Liu S, Tang J, Huang L, Xu Q, Ling X and Liu J: Cordyceps militaris alleviates severity of murine acute lung injury through miRNAs-mediated CXCR2 inhibition. Cell Physiol Biochem 36 2003-2011, 2015

40. Liu F, Xiong Y, Zhao Y, Tao L, Zhang Z, Zhang H, Liu Y, Feng G, $\mathrm{Li} \mathrm{B}, \mathrm{He} \mathrm{L}$, et al: Identification of aberrant microRNA expression pattern in pediatric gliomas by microarray. Diagn Pathol 8: 158, 2013.

41. Livak KJ and Schmittgen TD: Analysis of relative gene expression data using real-time quantitative PCR and the 2(-Delta Delta C(T)) method. Methods 25: 402-408, 2001.

42. Zhou KR, Liu S, Cai L, Bin L: ENCORI:The Encyclopedia of RNA Interactomes. http://starbase.sysu.edu.cn/index.php. Acessed April 15, 2020

43. Li JH, Liu S, Zhou H, Qu LH and Yang JH: starBase v2.0 Decoding miRNA-ceRNA, miRNA-ncRNA and protein-RNA interaction networks from large-scale CLIP-Seq data. Nucleic Acids Res 42 (Database Issue): D92-D97, 2014.

44. Zhang M, Weng W, Zhang Q, Wu Y, Ni S, Tan C, Xu M, Sun H, Liu C, Wei P and Du X: The lncRNA NEAT1 activates Wnt $/ \beta$-catenin signaling and promotes colorectal cancer progression via interacting with DDX 5. J Hematol Oncol 11: 113, 2018.

45. Dong P, Xiong Y, Yue J, Xu D, Ihira K, Konno Y, Kobayashi N, Todo Y and Watari H: Long noncoding RNA NEAT1 drives aggressive endometrial cancer progression via miR-361-regulated networks involving STAT3 and tumor microenvironment-related genes. J Exp Clin Cancer Res 38: 295, 2019.

46. Shin VY, Chen J, Cheuk IW, Siu MT, Ho CW, Wang X, Jin H and Kwong A: Long non-coding RNA NEAT1 confers oncogenic role in triple-negative breast cancer through modulating chemoresistance and cancer stemness. Cell Death Dis 10: 270, 2019

47. Di L, Liu LJ, Yan YM, Fu R, Li Y, Xu Y, Cheng YX and Wu ZQ: Discovery of a natural small-molecule compound that suppresses tumor EMT, stemness and metastasis by inhibiting TGF $\beta /$ BMP signaling in triple-negative breast cancer. J Exp Clin Cancer Res 38: 134, 2019.

48. Zhang Q, Mao Z and Sun J: NF-кB inhibitor, BAY11-7082, suppresses M2 tumor-associated macrophage induced EMT potential via miR-30a/NF- $\kappa$ B/Snail signaling in bladder cancer cells. Gene 710: 91-97, 2019.

49. Mitra T, Prasad P, Mukherjee P, Chaudhuri SR, Chatterji U and Roy SS: Stemness and chemoresistance are imparted to the OC cells through TGF $\beta 1$ driven EMT. J Cell Biochem 119: 5775-5787, 2018 
50. Zheng X, Zhang Y, Liu Y, Fang L, Li L, Sun J, Pan Z, Xin W and Huang P: HIF-2 $\alpha$ activated IncRNA NEAT1 promotes hepatocellular carcinoma cell invasion and metastasis by affecting the epithelial-mesenchymal transition. J Cell Biochem 119: 3247-3256, 2018.

51. Fu JW, Kong Y and Sun X: Long noncoding RNA NEAT1 is an unfavorable prognostic factor and regulates migration and invasion in gastric cancer. J Cancer Res Clin Oncol 142: 1571-1579, 2016.

52. Du Z, Sun T, Hacisuleyman E, Fei T, Wang X, Brown M, Rinn JL, Lee MG, Chen Y, Kantoff PW and Liu XS: Integrative analyses reveal a long noncoding RNA-mediated sponge regulatory network in prostate cancer. Nat Commun 7: 10982, 2016.

53. Ji S, Wang S, Zhao X and Lv L: Long noncoding RNA NEAT1 regulates the development of osteosarcoma through sponging miR-34a-5p to mediate HOXA13 expression as a competitive endogenous RNA. Mol Genet Genomic Med 7: e673, 2019.

54. Gibson MC and Perrimon N: Apicobasal polarization: Epithelial form and function. Curr Opin Cell Biol 15: 747-752, 2003.
55. Jurkiewicz D, Michalec K, Skowronek K and Nałęcz KA: Tight junction protein ZO-1 controls organic cation/carnitine transporter OCTN2 (SLC22A5) in a protein kinase C-dependent way. Biochim Biophys Acta Mol Cell Res 1864: 797-805, 2017.

56. Abraham V, Chou ML, George P, Pooler P, Zaman A, Savani RC and Koval M: Heterocellular gap junctional communication between alveolar epithelial cells. Am J Physiol Lung Cell Mol Physiol 280: L1085-L1093, 2001.

57. Guillemot L, Paschoud S, Pulimeno P, Foglia A and Citi S: The cytoplasmic plaque of tight junctions: A scaffolding and signalling center. Biochim Biophys Acta 1778: 601-613, 2008.

58. Doi Y, Yashiro M, Yamada N, Amano R, Noda S and Hirakawa K: VEGF-A/VEGFR-2 signaling plays an important role for the motility of pancreas cancer cells. Ann Surg Oncol 19: 2733-2743, 2012.

This work is licensed under a Creative Commons Attribution-NonCommercial-NoDerivatives 4.0 International (CC BY-NC-ND 4.0) License. 